\title{
Mijail Gorbachov: \\ De la tragedia de Chernobil \\ a la Carta a la Tierra
}

\author{
Francisco Javier Ibisate \\ Departamento de Economía \\ $U C A$, San Salvador
}

RESUMEN: El ex presidente de la Unión Soviética, Mijail Gorbachov realizó un valiente ejercicio de bonestidad política con su Perestroika, en el que se intentó democratizar el socialismo soviético. Gorbachov pagó el precio: fue desplazado del poder y repudiado por comunistas y liberales ortodoxos. No por ello el ex gobemante soviético se ba retirado de la vida pública. En su más reciente libro, Carta a la Tierra, Gorbachov pone al mundo sobre aviso de las grandes crisis producidas por el modelo económico y político imperante.

ABSTRACT: The former President of the Soviet Union, Mikbail Gorbachov accomplished a brave exercise of politic bonesty, leading bis Perestroika, an attempt to democratize the Soviet Socialism. Gorbachov paid the price: He was displaced from power and was despised by orthodox Communists and Liberals. But the former Soviet President did not retired from public life. In bis most recent book, Earth Dialogues, Gorbachov alerts the world from the great crisis produced by the ruling economic and political model. 


\section{Gorbachov, un hombre para el siglo XXI}

A finales de los ochenta, leíamos con nuestros alumnos la obra de Mijail Gorbachov, Perestroika: nuevas ideas para mi país y el mundo (Diana, México, 1987), publicación precedida por el Informe presentado por M. Gorbachov al Pleno del Comité Central del Partido: Tareas del Partido en la reforma radical de la administración económica (Novosti, Moscú, 1987). Cuatro años más tarde, luego del fallido golpe de Estado que le diera un grupo de halcones que él mismo había ascendido al poder, leímos su publicación: El golpe de agosto: la verdad y sus consecuencias (Diana, México 1991).

En su reciente publicación, Carta a la Tierra, Gorbachov recuerda ese momento: “A pesar del dolor que me causó mi destitución en 1991, debido a la traición de Boris Yeltsin, que hacía un doble juego al sabotear conscientemente mis esfuerzos por conseguir que se firmara el Acuerdo de la Unión entre las repúblicas que habían adquirido su independencia, abandoné el poder lleno de fe en el futuro". (Carta a la Tierra. Ediciones del Bronce, Barcelona, 2003) Gorbachov es una persona a quien traicionan grupos situados en la jerarquía del poder, que se oponían a la reforma radical (perestroika), a la presentación de la realidad nacional (glasnot) y a la nueva mentalidad internacional (novoye misleniye). Pese a ello, como escribe el autor, "abandoné el poder lleno de fe en el futuro".

Gorbachov ve su propia historia como "la vida de un campesino, un intelectual, un administrador, un hombre público $\mathrm{y}$, finalmente, la experiencia del dirigente de un Estado que ocupaba la sexta parte de la tierra emergida del planeta". Desde esta perspectiva Gorbachov plantea los "Tres retos del nuevo siglo". El pasado mes de septiembre, celebramos el sexagésimo aniversario de las Naciones Unidas y, más en concreto, las respuestas fallidas que han dado los 191 países miembros a los objetivos de la Declaración del Milenio. Desde su tribuna de intelectual y de Jefe de Estado, Gorbachov vuelve sobre esos grandes retos del Milenio, previa una reestructuración del calendario tradicional para integrar el pasado en el presente $y$ en el futuro.

"Rara vez, las fronteras de un siglo coinciden con las marcas del calendario. Para mí, el siglo XIX comenzó con la gran Revolución Francesa, y el XX con el estallido de la primera guerra mundial y la Gran Revolución de Octubre. Resumiendo, podemos decir que el siglo XIX estableció las bases del progreso y la democracia, mientras que el siglo 
$\mathrm{XX}$ fue el siglo de las guerras mundiales y las ideologías totalitarias, aunque también el siglo en que muchos pueblos del mundo se emanciparon del colonialismo y el siglo en el que las ideologías que vindican los derechos humanos y las ideas humanitarias en el ámbito social lograron un alcance planetario".

"Tampoco el inicio del siglo XXI se acomoda a los dictados del calendario; sus primeros signos fueron la perestroika, Chernobil y los atentados del 11 de septiembre contra las Torres Gemelas en Nueva York. Quizá a algunos pueda sorprender mi elección. Me explicaré. La perestroika y el nuevo pensamiento político que ésta trajo consigo pusieron fin a la carrera armamentística y a la división del planeta en dos grandes campos contendientes, inaugurando así la posibilidad de una genuina colaboración 'por encima de todas las barreras'. Chernobil significó una terrible advertencia de los peligros de la civilización tecnológica. Finalmente, el 11 de septiembre puso en evidencia las horribles consecuencias a las que pueden conducir la pobreza y la pérdida de los valores humanistas. Hoy, ningún ser humano, con independencia de la confesión religiosa a la que pertenezcamos o de la parte del mundo que habitemos, podemos desconocer nuestra responsabilidad con respecto a los tres principales retos del nuevo siglo".

A modo de preámbulo al primero de los retos, conviene recordar que el Premio Nobel de la Paz del año 2005 ha sido concedido a la Agencia Internacional de la Energía Atómica (AIEA) y a su director Mohamed El Baradei; el mundo está sometido a una amenaza nuclear: "A los sesenta años de las detonaciones atómicas en Japón y quince años después de la Guerra Fría, la amenaza de una pesadilla nuclear sigue siendo fuerte, señaló El Baradei. Nuestras estrategias de seguridad aún no están a la altura de las amenazas que enfrentamos. La globalización ha acabado con las barreras para el movimiento de bienes, ideas y personas, pero también ha retirado las barreras que confinaban y contenían las amenazas de seguridad".

Una de las principales noticias que trae enero de 2006 son las fuertes reacciones que está provocando a la Administración Bush y a los Jefes de Estado europeos la determinación del gobierno de Irán de reemprender el proceso de enriquecimiento de uranio, con fines civiles de generación de electricidad. Las negociaciones continuarán en el mes de enero y la Casa Blanca desea que la resolución pase el Consejo de Seguridad de Naciones Unidas. Mirando el reverso de la medalla, luego de los ataques 
del 11 de septiembre, Gorbachov, participando en la Conferencia sobre Transición y Consolidación Democrática, que tuvo lugar en Madrid, el mes de octubre de 2001, hizo la siguiente reflexión: "Las víctimas de los atentados del 11 de septiembre en los Estados Unidos no habrán muerto en vano si el mundo aprovecha la ocasión para mirarse en el espejo y reflexionar sobre sí mismo y establecer un compromiso moral sin caer en el pánico". El problema es que el mundo -especialmente Estados Unidos- no ha querido mirarse en el espejo de su historia pasada, reflexionar sobre sí mismo y establecer un compromiso moral sin caer en el pánico. Volvemos a los tres principales retos del nuevo siglo.

"El primero de estos retos consiste en la necesidad de mantener el mundo en paz, en reunir todos los esfuerzos de la comunidad internacional para conseguir el cese de los conflictos denominados locales, el no permitir que estos se extiendan como manchas de sangre. Hay que tener en cuenta que algunos de los países arrastrados a ese tipo de conflictos son estados que poseen la bomba atómica, o están a punto de poseerla; otros disponen de arsenales de armas químicas. La comunidad internacional debe también estar unida en la lucha contra el terrorismo, que no puede encontrar justificación alguna en consideraciones políticas o morales". Este primer reto coincide con el primer gran objetivo del Milenio: la paz, la seguridad y el desarme.

"El segundo reto consiste en la lucha contra la pobreza que hay en el mundo. ¿Cómo pueden esos mil millones de afortunados contemplar impertérritos los padecimientos que sufre la mitad de la población del planeta, gentes que viven con uno o dos dólares al día, que padecen hambre a diario y que, en muchos casos, carecen de condiciones sanitarias mínimas o de acceso al agua potable? ¿Cómo se puede permitir que en la era del Internet y de la globalización existan millones de niños que tengan que procurarse el sustento haciendo duros trabajos y carecen de acceso a la educación?". Este segundo reto refleja el segundo objetivo del Milenio: el desarrollo y la erradicación de la pobreza. Estos temas se desarrollan después en forma más detallada.

“El tercer reto son los problemas medioambientales. Los cambios climáticos que se están produciendo en el mundo son evidentes. Aumenta el número de cataclismos asociados a fenómenos de la naturaleza: tifones, tormentas, inundaciones, sequías; desaparecen numerosas especies vegetales y animales, los cascos polares se derriten, la polución ataca los océanos, la tala de bosques se produce a un ritmo de vértigo. Estamos inmersos en 
un grave conflicto con el propio medio que habitamos: la Madre Naturaleza". Este tercer reto aparece como el tercer objetivo del Milenio: La protección de nuestro entorno común. (Entorno económico mundial. UCA Editores 2005; pp. 185-188)

Como se ha repetido en tantas cumbres mundiales, en los foros sociales de Porto Alegre y en los foros económicos de Davos, también Gorbachov afirma: "Esos tres retos a los que se enfrenta hoy la civilización son interdependientes", y termina esta introducción con un detalle muy íntimo: "Mi libro es el resultado de los largos años de reflexión de una persona que, habiendo sido dirigente de una de las dos superpotencias del mundo, no olvidó jamás las tradiciones más humanas de la cultura rusa".

\section{2. "Como convencido socialdemócrata que soy"}

¿Quién es Mijail Gorbachov y cómo el ex Secretario General del Partido Comunista de la URSS puede definirse como un convencido socialdemócrata? Así se define Mijail Gorbachov y así recuerda su pasado político. "Estos mismos valores regían mi actividad en materia de política interna. La renuncia al monopolio del Partido Comunista sobre la esfera política y la implantación de un sistema pluripartidista, la convocatoria a celebrar elecciones libres, la renuncia al centralismo en las relaciones con las repúblicas que formaban parte de la Unión Soviética y al uso de la fuerza para ahogar los movimientos nacionalistas, la libertad de prensa, la libertad de culto, la puesta en marcha de las reformas económicas que condujeran a un tránsito paulatino hacia la economía de mercado, la reducción unilateral de las fuerzas armadas y la conversión de numerosas empresas del complejo armamentístico: tales fueron las principales transformaciones que se produjeron durante los años en que goberné el país. De una sociedad totalitaria en la que la disidencia era castigada por la ley, en la que los creyentes no podían desarrollar con éxito sus carreras profesionales, en la que cada palabra impresa estaba sometida a la censura del Partido y en la que había miles de libros de escritores y filósofos de todo el mundo encerrados en el 'spetsjiran' (infierno de biblioteca), pasamos a convertimos en una sociedad abierta. Lamentablemente, la perestroika no consiguió elevar el nivel de vida de los ciudadanos soviéticos, pero sí consiguió que se convirtieran en hombres libres".

Estaríamos regresando - por un momento- a inicios del siglo XX para recordar una verdad central de los socialismos históricos. Mijail Gorbachov se estaría situando del lado del socialdemócrata Karl Kaustky en su debate contra Lenin, dejando constancia de que "el siglo XX ha 
sido la historia de los irreconciliables hermanos socialistas". En su libro La dictadura del proletariado, que viera la luz en 1918, Kaustky dice: " $\mathrm{La}$ oposición entre las dos corrientes socialistas reposa en la oposición de dos métodos fundamentales distintos: el método democrático y el método dictatorial. Ambas corrientes quieren lo mismo: la emancipación del proletariado y con él el de la humanidad a través del socialismo. Pero la vía que unos escogen otros la consideran falsa y afirman que sólo puede llevar a la ruina. Reivindicar la libre discusión nos sitúa de entrada en el terreno de la democracia. El objetivo de la dictadura no es refutar la opinión contraria, sino suprimir violentamente su expresión. De este modo los métodos de la democracia y de la dictadura se oponen de una manera irreductible antes incluso de toda discusión. Una exige la discusión y la otra la niega". Ésta fue la vía dictatorial que escogió Lenin y mucho antes de 1989 hemos visto sus consecuencias.

Desde 1918, Kaustky anuncia y critica las consecuencias de esta dictadura para la construcción del socialismo. "La dictadura de una minoría siempre encuentra su más sólido apoyo en un ejército. Pero cuanto más coloca la fuerza en las armas en lugar de la mayoría, más fuerza a la oposición a buscar su salvación en las bayonetas y en la fuerza de sus puños en lugar de recurrir al voto que se le niega. Entonces la guerra civil se convierte en el medio de resolver los antagonismos políticos y sociales. Siempre y cuando no reine la más perfecta apatía política o el más perfecto desánimo, la dictadura de una minoría estará constantemente amenazada por golpes de Estado o por una guerrilla permanente. A partir de entonces ya no se conseguirá salir de la guerra civil y se verá confrontada en todo momento de ser aplastada por la guerra civil. Pero no existe mayor obstáculo para la construcción de una sociedad socialista que una guerra intestina. En una guerra civil, cada bando lucha por la existencia y al que pierde le amenaza su completa aniquilación. La conciencia de esta amenaza es lo que hace tan crueles las guerras".

Ésta fue una triste profecía de los más de veinticinco millones de desaparecidos en la era del terror de los verdugos Yhezow, Yagoda, Beria, instrumentos de Stalin en los treinta años de su "dictadura sobre el proletariado", como nos lo van a recordar M. Gorbachov y veinte años antes el propio Nikita Kruschov en su discurso el pleno del partido comunista, 1956. Entre tanta fidedigna literatura puede leerse la obra del historiador ruso, Roy Medvedev, Let history judge: the origins and consecuences of Stalinism. (Columbia University Press. New York, 1989) Después haremos referencia a otros foros soviéticos. 
La revolucionaria polaca Rosa Luxemburg sostenía, en contra de Lenin, que "la democracia era un ingrediente esencial de la revolución proletaria. Las dictaduras, fueran del tipo que fueran, y aunque fuera la revolución proletaria, no eran mas que una degeneración de los viejos ideales. Sin elecciones libres, sin una libertad de prensa y de reunión ilimitada, sin una lucha de opinión libre, la vida se marchita en todas las instituciones públicas, vegeta y la burocracia queda como único elemento activo". (Entomo económico mundial, Pp. 6-8)

Sea dicho entre paréntesis que este debate no es una polémica medieval, sino que tiene transcendental importancia para los siglos XX y XXI. Uno de los mayores daños que nos ha hecho el comunismo soviético es que intentó monopolizar el calificativo de "socialismo democrático", cuando en realidad y de acuerdo a sus mismos foros políticos, se convirtieron en la negación de un socialismo democrático de rostro humano. La segunda triste consecuencia y error histórico es que para las aristocracias capitalistas no hay más socialismo que el soviético $\mathrm{y}$, en consecuencia, el neoliberalismo es 'el fin de la historia'.

La cita antes hecha de Gorbachov nos trae al recuerdo dos citas más recientes. En 1968 los tanques soviéticos invaden Checoeslovaquia y tronchan la "Primavera de Praga", un modelo de socialismo de rostro humano. Ota Sik, inspirador del modelo y exilado a Suiza, escribe: "El camino real para la superación, o al menos para debilitar el acceso burocrático exige la superación del monopolio leninista del Estado, que nada tiene en común con el socialismo, y que está construido sobre el supuesto de una élite de poder que todo lo sabe, todo lo planifica y todo lo decide. Cuando se hayan podido modificar esos fundamentos falsamente postulados del sistema comunista y se imponga una democracia total de la economía y de la política, podrá alcanzarse una verdadera formación socialista". (Angumentos para una tercera vía, E. Dopesa, Barcelona, 1975; p. 141. Cfr. Entomo económico mundial, p. 38)

En 1989, tiene lugar el Foro de Moscú: el imperio se hace la perestroika. Entre las múltiples ponencias una de las más críticas es la de Yuri Kariakin, diputado del Congreso y partidario de la perestroika. "Partimos de la idea, hace setenta años, de que había que acabar con la propiedad privada, y lo que hicimos fue fusilar el interés personal; fusilamos el trabajo. Partimos de la idea de que había que fusilar la democracia burguesa y con ello fusilamos todo el ordenamiento legal, dejando a la sociedad sin leyes. Hay que fusilar la religión, dijimos nosotros, y fusilamos la moral, y el 
socialismo fue inhumano, por no decir antihumano, y ahora cosechamos los frutos de esas ideas, inicialmente nobles. Nos dimos cuenta de ello sólo cuando nọs encontramos no ya en el umbral de la catástrofe, sino en su sima más profunda. Sólo entonces empezamos a entender que nosotros ocupamos los últimos lugares de todos los índices de progreso social. ¿Por qué nos hallamos en los últimos lugares? ¿Por qué nuestra sociedad ocupa ahora el primer lugar en el engaño, en el autoengaño?".

"Si los que toman las decisiones en este país escucharan lo que estamos diciendo en esta conferencia, primero, no nos entenderían $y$, segundo, tendrían miedo de lo que estamos diciendo. Esta sociedad que tropieza con su propia muerte no tiene otras vías de conocimiento de lo que pasa, no hay otro camino de salvación que el de tropezar con la propia muerte; y otra vez vemos en el Congreso a diputados que se escuchan a sí mismos, porque queremos que nos vean mejor de lo que somos. El diagnóstico también es falso aquí. El diagnóstico se percibe como la causa principal de la enfermedad. Los diputados comprenden que es preciso controlar la reforma política, porque si la perestroika supera o descarta la actual superestructura política sólo entonces será posible solucionar los problemas económicos. En definitiva, todos los planteamientos, todos los diagnósticos tropiezan, quiérase o no, en la necesidad de la renovación de esa mayoría no calificada en el Congreso y fuera del Congreso, que es la que detenta el poder". (Entomo económico mundial, 2005; p. 39)

Seis meses después de la ponencia de Yuri Kariakin cae el muro de Berlín, noviembre 1989, y dos años después se firma en Minsk la disolución de la URSS, del Pacto de Varsovia y el CAEM (su mercado común) se desvanece cuando en la Rusia de Boris Yeltsin no hay ni plan ni mercado. Esta es la herencia que recibe Mijail Gorbachov en 1985, cuando es elegido Secretario General del Partido Comunista de la URSS. ¿Qué va a hacer Mijail Gorbachov "como convencido socialdemócrata que soy"?. Gorbachov va a ser un hombre que escucha, dialoga, reflexiona y aprende. En el diccionario ruso la palabra "perestroika" marca una graduación: reforma, reestructuración y revolución económica. Los tres conceptos y políticas que va a introducir Gorbachov son perestroika, glasnot (decir la verdad) y novoye misleniye (nueva mentalidad). Sea dicho (entre paréntesis) que al hablar del fallido socialismo soviético, le estamos hablando al actual capitalismo neoliberal; eso es lo que hará Mijail Gorbachov en la obra que estamos comentando. Pero, M. Gorbachov tuvo bastantes precursores. 
La URSS y el bloque soviético contaron con grandes economistas, dos de ellos Premios Nobel de Economía: Vassily Leontief en cuanto iniciador o inspirador de las matrices insumo-producto, y Leonidas Kantorovich como iniciador de la programación lineal. Para desdicha de la economía soviética, Leontief desarrolla sus matrices input-output en Estados Unidos, y Leonidas Kantorovich será uno de los grandes ingenieros-economistas perseguido en la década de los cuarenta. Sirva esto a recordar que, década tras década, grandes economistas solicitarán y plantearán programas de reformas económicas (perestroikas) y serán silenciados, exilados o confinados en prisión. El célebre analista del capitalismo y descubridor de las ondas largas, Nikolai Kondratief, será exilado junto con otros grandes economistas en la década de los trẹinta y su nombre aparece en la obra del Archipiélago Gulag, de Alexander Solsenitzin. Similar suerte correrá un grupo de ingenieros proyectistas en la década de los cuarenta, compañeros de L. Kantorovich, acusados de introducir normas económicas burguesas, cuando en realidad proponían alternativas para disminuir costos de inversión y precios racionales. En 1965 se aprueba oficialmente la llamada Reforma Liberman, presentada por Evsei Liberman de la Universidad de Jarkov. La ratificación oficial para toda la URSS se hace en 1965 y cuando Polonia, Hungría y, sobre todo, Ota Sik, en Checoeslovaquia, la traducen en un modelo de socialismo democrático, los tanques rusos tronchan la Primavera de Praga. Una revista cuenta que en 1983 muere el inspirador de la reforma Evsei Liberman "alone and forgotten". Ota Sik se refugia en Suiza y el reformista polaco Wlodzimier Brus lo hará en Holanda. A partir de 1970 se inicia "la era del estancamiento Brezhnev", que es la herencia que recibe M. Gorbachov.

Una de las grandes tareas que inicia M. Gorbachov es la "autocrítica". El mayor problema y la mayor debilidad política que tuvo el comunismo soviético es haber cerrado la puerta — década tras década- a la autocrítica, a la glasnot, a decir la verdad en su doble vertiente: decir la verdad desde arriba y escuchar la verdad que viene desde abajo. Un refrán popular nuso decía: "nuestro pasado es imprevisible"; fue un pueblo a quien se le ocultó la verdad. Esta es una lección importante porque se repite la misma historia en los ortodoxos de izquierda y en los ortodoxos de derecha. Está será la tarea que le tocará a Gorbachov: abrir la puerta a la verdad.

Cuando regresemos a su Carta a la Tierra, nos podemos preguntar ¿con qué autoridad cuenta $\mathrm{M}$. Gorbachov para hacer una serie de propuestas y recomendaciones al mundo de hoy, si su perestroika fue el 
'canto del cisne' de un agonizante comunismo soviético? La autoridad le viene de que tuvo la virtud de hacer autocrítica y decir la verdad. En junio de 1987 expone ante el Pleno del Partido el informe económico: Tareas del Partido en la reforma radical de la administración económica. Quien tenga a bien leer este informe de setenta páginas, verá que se hacen críticas concretas, con nombres y apellidos, sobre el defectuoso comportamiento de una multiplicidad de ministerios y direcciones administrativas. La segunda gran parte se centra en "la reforma radical de la administración de la economía, importantísimo eslabón del proceso de renovación".

Se trata de la reforma de las funciones de la dirección centralizada de la economía, en la planificación nacional, en la fijación de los precios, en las finanzas, crédito y circulación monetaria. Algunos economistas, como Stanislav Shatalin, prepararán nuevos programas, pero como indicara Ota Sik, una parte importante de la jerarquía del Partido se resiste a esta reforma económica. No es fácil introducir la democracia económica luego de setenta años de dictadura del partido único. El lema de M. Gorbachov será: "más socialismo, más democracia". Con toda razón se dirá en el foro de Moscú que "socialismo y partido único es algo contradictorio".

Si Gorbachov no logró ser profeta en su tierra, sin duda ha tenido éxito mayor con su obra Perestroika: Nuevas ideas para mi país y el mundo. Sigue teniendo plena actualidad la segunda parte: "El pensamiento nuevo y el mundo" y muchos puntos de sus cinco últimos capítulos. Capítulo $3^{\circ}$ "¿Cómo vemos el mundo actual?". Capítulo $5^{\circ}$ "El Tercer Mundo en la Comunidad Internacional". Capítulo $6^{\circ}$ "Europa en la política exterior soviética". Capítulo 70 "Problemas del desarme y relaciones soviéticonorte- americanas". En su Carta a la Tierra, M. Gorbachov nos va a explicar algunos de estos ritulares.

Luego de Perestroika se abre una era de transparencia política. La Academia de Ciencias de la URSS publica una colección: Historia de la URSS. Problemas centrales de la bistoria rusa y soviética. Nuevos estudios y enfoques. (E. Nauka, Moscú 1990) Entre ellos aparece "la mesa redonda de historiadores soviéticos". En 1988 tiene lugar el Foro de Barcelona, donde la riada sube hasta la imagen de Lenin. En 1989 tiene lugar el mencionado Foro de Moscú y en 1990, luego de una encuesta macroeuropea, tiene lugar el Foro de la Sorbona en París. En agosto de 1991 aparece en los diarios europeos la carta de Stanislav Shatalin, escrita a raíz del golpe de Estado a M. Gorbachov. (Entomo económico mundial; PP. 35-42) 
Para entender mejor al Mijail Gorbachov de Carta a la Tierra, traslado unos párrafos de su comentario al golpe de agosto: "Yo soy una de esas personas que nunca ocultan sus convicciones. Soy partidario confirmado de la idea de socialismo. Es una idea que ha venido abriéndose camino por sí misma durante varios siglos. Tiene muchos seguidores y éstos han presidido los Gobiernos de numerosos Estados. Existen varias ramas del movimiento socialista, porque no es una especie de "modelo", al que deba adecuarse la sociedad. No, es una idea, precisamente una idea que abarca valores desarrollados en el curso de la búsqueda de una sociedad más justa y un mundo mejor. Es una idea que extrae energía de muchos hallazgos del cristianismo y de otras tendencias filosóficas. La idea de socialización está presente en muchos movimientos políticos y sociales".

"Yo me considero a mí mismo un demócrata y baso mi pensamiento en que la idea socialista sin democracia y sin una solución correcta y fiable de los problemas sociales no es posible. En consecuencia, creo que debemos reconocer que fue el género de socialismo que teníamos en nuestro país lo que demostró ser un fracaso, y no la idea socialista en sí. La pregunta se plantea algunas veces: ¿fue la Revolución de Octubre una catástrofe, o fue después de todo una genuina revolución? Comprendo el motivo que esta cuestión resucite; es debido a que los resultados históricos no fueron los resultados de llevar a término las "ideas de octubre", una auténtica revolución del pueblo: lo fueron de la forzada introducción del modelo estalinista de sociedad. Uno no debe confundir ambas cosas".

"En lo que concierne a mis puntos de vista, a lo largo de los años lo he hecho todo para poner fin al estalinismo. Sin esto no tienen sentido pensar siquiera en llevar a la realidad la idea socialista. La vida en cada país debe ser la obra de su propia gente. Constituye hoy nuestro deber entender y desarrollar los procesos de democratización en todas las esferas. Pienso que todo ello viene a ser como un movimiento hacia una mayor justicia para el individuo y la afirmación de sus derechos y libertades y de los derechos y libertades de los pueblos. Y que es ciertamente un avance en la dirección de realizar la idea socialista. Tal es mi interpretación del problema". (pp. 58-60)

Después de haber escuchado al Gorbachov de Perestroika escuchamos ahora al Gorbachov de Carta a la Tierra, recordando tres frases antes citadas, que unen el pasado con el presente y el futuro. "Mi libro es el resultado de los largos años de reflexión de una persona que, habiendo sido dirigente de una de las dos superpotencias del mundo, no olvidó

\section{1}

Mljall Gorbachov: De la hagedia de Chemobll a la Corto alo lierio 
jamás las tradiciones más humanas de la cultura rusa". Este libro "me da la posibilidad de articular una suerte de síntesis de las aspiraciones de toda una vida: la vida de un campesino, un intelectual, un administrador, un hombre público y, finalmente la experiencia del dirigente de un Estado que ocupaba la sexta parte de la tierra emergida del planeta". "A pesar del dolor que me causó mi destitución en 1991, debido a la traición de Boris Yeltsin, abandoné el poder lleno de fe en el futuro".

\section{Mijail Gorbachov en su infancia}

Traslado literalmente algunos párrafos para escuchar a un Gorbachov más cercano. 'Nací y crecí en el Cáucaso Norte, en la región de Stávropol que, desde la más remota antigüedad hasta nuestros días, ha sido testigo de las más diversas invasiones... Aparte de los rusos, la habitan ucranianos, griegos, armenios y numerosos pueblos del Cáucaso Norte: karachevos, cherkesos, osetios, nogayos, chechenos y otros. Mi patria chica me sirvió de primera lección de tolerancia y de respeto hacia otras nacionalidades, lenguas, costumbres y religiones; en un territorio tan pequeño estaban representadas las tres ramas de la ortodoxia y el Islam, además de una decena de lenguas y culturas populares"

"Mi infancia transcurrió en la pobreza, en una khata tradicional con el suelo de tierra, en la que dormíamos todos sobre la estufa. En invierno acogíamos a los terneros en la entrada; en primavera dejábamos entrar a las gallinas y a los patos. En 1933, siendo yo todavía un niño, el hambre se abatió sobre Stávropol, un hambre que en la vecina Ucrania se calificaba sin tapujos de "hambruna". Según una buena parte de los historiadores, se trataba de un hambre provocada y organizada oficialmente desde el gobierno. Se confiscaron las cosechas, grano y otros productos para alimentar a la masa obrera abocada a la acelerada industrialización del país, y acabar al mismo tiempo a cualquier conato de resistencia a la colectivización. El primer efecto de la colectivización fue la destrucción de los usos tradicionales de la vida campesina, además de venir acompañada del destierro a Siberia de los campesinos más prósperos y eficaces, los kulaks, con la consiguiente desarticulación de la producción agrícola. Durante ese terrible año, casi la mitad de mi ciudad natal, Privolnoye, murieron de hambre, entre ellos dos hermanas y el hermano de mi padre".

Al hambre le siguió otra prueba más: las purgas estalinistas. Mis dos abuelos fueron arrestados bajo acusaciones carentes de cualquier sustento real, si bien afortunadamente sobrevivieron; no tuvo esta misma fortuna 
el abuelo de mi esposa Raisa, que fue fusilado y al que sólo se rehabilitó en 1988. En 1941 le sobrevino otra enorme tragedia al pueblo soviético: la agresión de la Alemania nazi. Mi padre marchó al frente de batalla, mientras que yo, todavía un niño, quedé junto a mi madre y el resto de la familia, padeciendo la ocupación alemana, el hambre, el constante temor por la suerte de mi padre... y un profundo dolor por el destino de nuestro país".

“¿Cuáles son los recuerdos que mejor guardo de aquellos años terribles? Sin duda alguna, el primer invierno de la guerra, de una rigurosidad especial, como si la propia naturaleza se hubiera levantado contra los invasores. Hambre y miseria. La práctica totalidad de la cosecha se entregaba al gobierno para alimentar al ejército y a los obreros que trabajaban en la industria militar. Incluso se suspendió el suministro de los bienes de primera necesidad". Gorbachov comenta que "la repugnancia que siente por la guerra" se generó al contemplar con otros compañeros los cuerpos descompuestos de soldados caídos en combate, así como los infinitos kilómetros de ruinas, en su viaje hacia Moscú. Otra mueca del rostro de la guerra.

Conviene agregar otros datos comentados por el último Secretario General del PCUS, que no solían aparecer en el antiguo Manual de Economía Política de la URSS. "A los quince años empecé a trabajar durante los veranos con mi padre conduciendo maquinaria agrícola. Todos los peones del koljós trabajaban duramente, si bien no se les pagaba en efectivo por su trabajo y el pago que percibían "en especie", es decir, en productos agrícolas, era mísero. Las familias campesinas sobrevivían gracias a las huertas domésticas y todavía tenían que entregar al Estado parte de la cosecha. También los árboles frutales estaban gravados con un impuesto, a pesar de que no daban frutos todos los años.

La utopía socialista, en cuyo nombre millones de campesinos apoyaron a la revolución que les prometió dar tierras, terminó por convertirse en un régimen de servidumbre estalinista. Los campesinos, totalmente sometidos a la brutal dependencia del Estado, ni siquiera podían emigrar a las ciudades: el famoso pasaporte interno, sin el cual era imposible encontrar un empleo y obtener la autorización para cambiar de residencia, no se concedía nunca. Comencé a tomar conciencia muy temprano, aunque fuera de manera todavía imprecisa, de que el campesinado soviético se había convertido en víctima de la injusticia social, aunque entonces creía que se trataba de una situación provisional y que el futuro radiante terminaria por llegar". 
Tratándose de un libro que lleva por nombre Carta a la Tierra, Gorbachov dirá que "soy un hombre relacionado con la naturaleza desde la más tierna infancia". Luego de comentar una secuencia de desastres naturales, hace la siguiente confesión: "A medida que yo iba subiendo por la escalera del mando, se me iba haciendo evidente la magnitud de la catástrofe económica, social y ecológica en la que se había hundido la Unión Soviérica. Es necesario recordar que casi toda la información concerniente a la verdadera situación del país era secreta por aquél entonces y sólo en 1970, cuando me convertí en diputado del Sóviet Supremo de la URSS, y miembro de la comisión para la protección de la naturaleza, tuve acceso parcial por primera vez. Fue sólo al ocupar el puesto de secretario general del Comité Central del Partido Comunista de la Unión Soviética que ese acceso fue completo".

'Nuestra tierra 'nutricia' estaba agotada y abandonada. Las principales prioridades del gobierno eran la industria pesada, alimento del complejo armamentístico y la explotación de yacimientos minerales. Millones de hectáreas fueron 'expropiadas' por el ejército para realizar ensayos nucleares. Decenas de millones de hectáreas antes fértiles sucumbieron ante las más primitivas técnicas de cultivo. El uso demencial y masivo de pesticidas trajo la contaminación generalizada de tierras cultivables, ríos y lagos, causando daños irreparables a la flora y a la fauna. iY la población de las regiones que fueron convertidas en campos de pruebas de armas nucleares y químicas, como es el caso de la región de Cheliabinsk, sin que se avisara a la población de los peligros que corría! Estos hechos se mantuvieron en secreto durante casi treinta años".

"Confieso que cuando ese episodio fue hecho público me sentí horrorizado. La falta de transparencia informativa permitía a los dirigentes del país perpetrar los más diabólicos abusos, contando con el más absoluto silencio de una prensa controlada por la censura. iY encima los funcionarios del gobierno y del partido obtenían condecoraciones por tales 'hazañas'! En 1985 fui elegido para encabezar el Partido Comunista, lo que de hecho me situaba a la cabeza de la URSS. Por aquel entonces ya tenía meditadas las principales ideas necesarias para conducir la reforma del país, que se resumían en una firme convicción: iNo podemos seguir viviendo así! Entonces propuse a la sociedad tres objetivos: transparencia, perestroika y aceleración". Hemos recordado antes cómo Gorbachov intentó llevar a cabo este triple objetivo y como las derechas reaccionarias tramaron el golpe fallido, aprovechado por Boris Yeltsin. 
Carta a la Tierra tiene un triste antecedente nacional. En el mes de. abril de 1986, cuando llevaba tan sólo un año en el poder, se abatió sobre nuestro país la catástrofe de Chernobil, que constituyó para mí - como confío lo fue también para toda la humanidad- la más dura de las lecciones. Chernobil hizo de mí otro hombre". Gorbachov afirma rotundamente que tanto él como su equipo decidieron "publicar los datos y las cifras de la catástrofe según nos fueran llegando. En segundo lugar, mi fe en la absoluta seguridad de la técnica se vio gravemente quebrantada". No era cierta la afirmación de algunos físicos rusos, "de que se podía levantar una central nuclear incluso en la propia plaza Roja. Y finalmente, Chernobil, demostrando enérgicamente que constituimos una única humanidad que habita un único espacio físico, fortaleció aún más mi resolución de construir la base de nuevas relaciones internacionales. Seguían llenándose los arsenales y cada vez era mayor el número de países que se sumaba al "club nuclear".

"Tuve la primera ocasión de plantear mi concepción del nuevo pensamiento político, fundamentado en mis propias convicciones y apoyada en los estudios desarrollados por numerosos científicos de varios organismos oficiales, cuando viajé a Londres en el mes de diciembre de 1984, encabezando una delegación del Sóviet Supremo, antes de ser elegido secretario general del Partido. Tras mantener una charla con la primer ministro Margaret Thatcher, pronuncié un discurso ante los parlamentarios británicos, en el que sostuve que en el siglo nuclear no podía haber vencedores, qừe las relaciones internacionales no podían seguir enmarcadas en los esquemas de la guerra fría y que estábamos decididos a emprender la puesta en práctica de cualquier esquema de reducción de armamentos, especialmente del armamento nuclear, en condiciones de paridad con nuestros socios occidentales".

"Ya entonces pronuncié una frase que continuó siendo mi credo: "A pesar de todo aquello que nos separa, habitamos un mismo planeta. Europa es nuestra casa común. Es precisamente eso: Una casa y no un teatro de operaciones militares. En particular, afirmábamos que no hay valor superior al de la vida humana, que la renuncia a la violencia debe erigirse en el principio fundacional de la coexistencia entre los individuos y los pueblos, que debe sustituir al "equilibrio del terror" por un sistema global de seguridad internacional. A pesar del dolor que me causó mi destitución en 1991, abandoné el poder lleno de fe en el futuro". Éste es el Mijail Gorbachov, Premio Nobel de la Paz, que ahora nos va a decir "cómo vemos el mundo actual". 


\section{Una crisis global}

Para Mijail Gorbachov, la palabra "crisis" no significa propiamente una situación caótica en las áreas política, económica y social, sino el negarse a evaluar, juzgar, aceptar la realidad para llevar a cabo las reformas necesarias y el cambio de mentalidad.

Gorbachov teme que en la globalización neoliberal se repita la misma crisis que en el socialismo soviético; por eso dice que "me embarga la alarma y la desilusión". "Parecería que el fin de la guerra fría, cuyo símbolo más visible fue la caída del Muro de Berlín, permitiría a la humanidad concebir esperanzas para el futuro. Parecería también que la comunidad internacional, libre del temor ante la amenaza nuclear y apartada de los caminos del antagonismo ideológico, iba a dar por terminada la carrera armamentística, a encaminarse por la senda del desarrollo sostenible, a adoptar medidas urgentes para erradicar la pobreza y la catastrófica contaminación del medio ambiente, a transformar el carácter de la globalización, incluyendo conceptos como los derechos humanos y la libertad individual".

"Las celebraciones por el fin del comunismo se prolongaron durante demasiado tiempo y sus fastos ocultaron la complejidad del mundo, sus problemas y contradicciones. La pobreza y el atraso económico, al igual que los ineludibles problemas ecológicos, se vieron relegados hacia la periferia de la conciencia social. En resumen, en lugar de ingresar en un nuevo orden mundial, nos hemos hundido en un "nuevo desorden mundial", en el que muchos países, en lugar de adoptar un enfoque global del problema de la supervivencia de la humanidad, se han entregado a astutas maniobras que les aseguren ventajas a expensas de los demás. El 11 de septiembre ha evidenciado la inconsistencia de la idea de un mundo unipolar. Ese día se puso de manifiesto que incluso un país como Estados Unidos, el más poderoso del planeta, es vulnerable e incapaz de contrarrestar en solitario la amenaza del terrorismo internacional". Al analizar la década que media entre el fin de la guerra fría y el 11 de septiembre Gorbachov descubre cuatro crisis mundiales.

\section{Una crisis política}

Aunque G. W, Bush y V. Putin se han comprometido a la futura reducción de los arsenales nucleares, "el último decenio ha demostrado que el fin de la guerra fría no ha significado en ningún caso el inicio del reino de la paz sobre el planeta". Hemos sido testigos de los más crueles

Realldad 107, 2006 
conflictos y guerras en Europa, Asia y América: Israel-Palestina, Yugoslavia, Chechenia, Indonesia, Cachemira, el Golfo Pérsico, Ruanda, Afganistán.

"Analizaré uno de ellos, el de Yugoslavia, porque en él se reflejan las perniciosas tendencias del orden mundial vigente. Una de esas tendencias viene firmada por los intentos de algunos países de poner orden en el mundo por la fuerza, rigiéndose por "consideraciones humanitarias", y la ausencia de un contrapeso potencial de la comunidad internacional a esas acciones. Precisamente, ese principio fue el que provocó que se ejecutara la acción militar contra Yugoslavia, a partir de la situación en Kosovo. Se trata de personas empujadas a actuar bajo condiciones inhumanas y que a menudo pierden su rostro humano. Nuestro deber era detenerlos llegados a ese último límite e impedir que se produjera lo irreparable. En lugar de eso, lo que se hizo fue utilizar el armamento más modemo en una Europa que no había conocido la guerra durante medio siglo. Según cálculos del diario Times, cada día de guerra contra Yugoslavia, en 1999, le costó a la OTAN mil millones de dólares. Una guerra, subrayo, que se pudo haber evitado. ¿Acaso no era más humano y razonable dedicar ese dinero a la lucha contra la pobreza, el desempleo, la drogadicción o el sida en la antigua Yugoslavia?". Ese es el meollo de la crisis política moral.

"Hay otro aspecto de las acciones de la OTAN que conviene considerar: el aspecto ecológico. A pesar de que tras la operación "Tormenta del Desierto", en Irak, ya eran conocidos los efectos que el uranio empobrecido tiene sobre el entorno, habiendo desatado una ola de enfermedades entre los efectivos norteamericanos y de otros contingentes occidentales que participaron en esa campaña, así como entre la población iraquí, esos armamentos volvieron a ser utilizados en Yugoslavia. Los bombardeos de la OTAN atacaron las refinerías de petróleo, empresas petroquímicas y farmacéuticas, i¿Quién responderá por el daño ocasionado a la salud de la población yugoslava y los países vecinos?! ¿Qué lección pueden sacar muchos países de la tragedia yugoslava? Me temo que sólo una: para evitar el destino de Yugoslavia, los países situados en el llamado "umbral nuclear" se esforzarán por hacerse con armas nucleares lo antes posible y a cualquier precio, y los países pobres harán lo propio respecto a las armas químicas y bacteriológicas. Esto significa que sobre el planeta se ciemen nuevos temores y nuevos peligros". 
Con estas reflexiones, Mijail Gorbachov está criticando una guerra en la misma forma en que lo hiciera Koffi Annan en la cumbre del Milenio, septiembre 2000, como generadora de "anarquía mundial", cuyas consecuencias se querían evaluar en la $58^{2}$ asamblea de la ONU, 2003, y en la más reciente cumbre del $60^{\circ}$ aniversario de Naciones Unidas. Las guerras libradas en Serbia-Kosovo, Afganistán e Irak están debilitando las funciones de Naciones Unidas porque se inician sin autorización del Consejo de Seguridad y porque las más poderosas potencias se niegan a ratificar los estatutos de la Corte Penal Internacional. (ECA 2005; pp. 859-865) En la introducción a Carta a la Tierra se hace una primera referencia a las funciones de la ONU. "No debemos cejar en nuestro empeño y sí velar atentamente por el papel de las Naciones Unidas como único ente dotado de la autoridad para decidir cuándo se han agotado los canales diplomáticos y si éstos se han agotado de veras, así como el único capacitado para adoptar la decisión extrema de recurrir al conflicto armado sólo como único recurso".

\section{Una crisis económica}

"El fin de la guerra fría y el impresionante crecimiento que han experimentado las tecnologías de la información y las telecomunicaciones han dado un serio impulso al desarrollo de la globalización. Y, sin embargo, para la humanidad en general se ha tratado de un decenio marcado por el crecimiento de la desigualdad entre el Norte y el Sur, entre los ricos y los pobres. La globalización y la actividad de un mercado libre global e incontrolado, que "succiona" el capital y los "cerebros" del mundo entero en beneficio de unos pocos países ricos y poderosos, se traduce en el crecimiento acelerado de la falla que separa a los ricos de los pobres. Hace apenas una generación, el veinte por ciento de la población del planeta era treinta veces más rico que el veinte por ciento de los pobres. Hoy día esa diferencia se ha multiplicado exactamente por dos".

Carta a la Tierra lleva como subtítulo: "A los pobres se les debe dar la oportunidad de recuperar su dignidad". En la parte introductoria, Gorbachov nos advierte: "La última de esas batallas es, quizás, la más crucial de todas, y tendrá una influencia decisiva en el resultado de todas las otras. A los millones de personas que sobreviven a duras penas en chabolas, campos de refugiados o en aisladas áreas rurales repartidas por todo el mundo debe dársele la oportunidad de acceder al desarrollo y participar de un mundo globalizado. ¿Qué incentivos tienen esas personas para abogar por la democracia, la tolerancia y la paz, en lugar de optar 
por la violencia y los extremismos, cuando los países prósperos mantienen barreras comerciales y políticas de subsidio agrario que los ahogan, a la vez que hacen la vista gorda a su propio consumo desmedido y su dependencia de los combustibles fósiles? ¿Cómo no van esas gentes a sentirse airadas y alienadas ante los nada generosos enfoques hacia cuestiones tales como el endeudamiento y el acceso a medicamentos fundamentales? Tales políticas no conceden el mismo peso a la vida humana en todas las partes del mundo. De hecho, la pobreza en sí misma constituye una forma terrible de violencia contra la humanidad. Las personas que carecen de agua potable o medicamentos básicos no viven en paz. La pobreza, como la guerra, destruye vidas y genera descontento".

En la misma introducción y luego de hacer una breve referencia a la fallida Cumbre de la Tierra en Johannesburgo, celebrada el año 2002, Gorbachov vuelve sobre la crisis económica como raíz de otras crisis. "La cuestión resta de ser tan sencilla como reducir el número de armamentos, dar caza a los terroristas o destituir a los líderes que les brindan apoyo. La cuestión, más bien, radica en atacar la raíz de los conflictos, unas raíces que se hunden en las desigualdades que padece el mundo: la distribución y la redistribución desigual de la riqueza, la falta de reconocimiento de la legalidad internacional, incluyendo los derechos humanos básicos, la falta de provisión para dar respuesta a las necesidades humanas, incluyendo el agua, la energía y la educación de la que carecen más de dos mil millones de personas. Se debe dar a los pobres la posibilidad de recuperar su dignidad. De lo contrario, las desigualdades globales entre los ricos y los pobres, así como entre el Norte y el Sur, y la renuncia a adherirse a los valores dernocráticos, están abonando el terreno para el surgimiento de terrorismos y extremismos de toda laya".

Al comentar la crisis económica, M. Gorbachov hace una aplicación a la Rusia de Boris Yeltsin. "El liberalismo salvaje, estimulado por las instituciones financieras Internacionales, ha engendrado un gran número de crisis económicas, como ha sucedido, por ejemplo, en el Sudeste asiático, en Argentina y en Rusia. Rusia le ha mostrado claramente al mundo cuál es el precio de ser un "alumno ejemplar" de las concepciones liberales de la economía en un país carente de instituciones democráticas sólidas y tradición de un capitalismo "con rostro humano". En menos de diez años, la población rusa ha sido saqueada y arruinada tres veces. También disminuyeron en el país la esperanza de vida y la natalidad, y 
apareció un fenómeno como el de las hordas de niños abandonados, lacra que desconocíamos desde los años de la guerra civil, y ello cuando Rusia ingresó en el mercado mundial, siendo un país dueño de un elevado potencial industrial, habitado por una población que gozaba de un alto nivel de instrucción y poseedor de vastísimos recursos naturales. Otros muchos países, arrastrados al proceso de la globalización, se han visto mucho más desprotegidos ante este fenómeno”.

\section{Una crisis social}

Con esta crisis, Gorbachov nos acerca a ese fenómeno que algunos quieren llamar choque de civilizaciones y más directamente al terror a escala mundial. Algunos problemas aquí mencionados nos recuerdan el foro social mundial tenido en Bombay, India. Por respeto a las ideas y al estilo lúcido de Gorbachov, sigo haciendo una transferencia literal de sus reflexiones. "Con el fin de la guerra fría, yo confiaba que las gigantescas sumas que gastaban los países desarrollados en la carrera armamentística iban a dirigirse, siquiera en parte, a la eliminación de la pobreza en el mundo. Me parecía que las civilizaciones formadas en los valores cristianos del amor al prójimo no podían continuar asistiendo en silencio al hambre que padecen ochocientos millones de personas, a la realidad de los más de mil millones de personas que carecen de acceso al agua potable, de los dos mil millones que no están conectados a redes de energía eléctrica o los tres mil millones, justo la mitad de la humanidad, que carecen de las comodidades más elementales".

La siguiente cuña es un lúcido aporte de un jefe de Estado: "En una ocasión, Winston Churchill definió la diferencia entre un estadista y un político; el político piensa en las próximas elecciones, mientras que el estadista piensa en el futuro. Parece que el mundo contemporáneo sufre hoy un grave déficit de estadistas y un exceso de políticos. Las consideraciones preelectorales de los últimos, unida a la psicología consumista de los ciudadanos de los países desarrollados, dominan sobre el elemental sentimiento de justicia".

En la fallida cumbre del sexagésimo aniversario de Naciones Unidas, los 191 países miembros no pudieron formular una definición de qué es "terrorismo", y el borrador de definición que se presentó a los delegados tampoco es un texto muy clarividente: terrorismo es "todo acto que obedezca a la intención de causar la muerte y graves daños corporales a civiles no combatientes, con el objetivo de intimidar a una población u 
obligar a un gobierno o a una organización internacional a realizar o abstenerse de realizar un acto". (ECA 2005, p. 864) Sin proponer una definición, M. Gorbachov, igual que otros Premios Nobel de la Paz, nos presentan la génesis de ese pasado y presente fenómeno que llamamos terrorismo.

"La globalización, al haber penetrado en los otrora cerrados 'cotos de civilizaciones' conduce muchas veces a la alteración, cuando no directamente a la ruina, de los fundamentos tradicionales de ciertas sociedades. Cuando esa ruina viene acompañada del empeoramiento de las condiciones de vida de grandes grupos de la población, las personas se vuelven permeables a las ideas del fundamentalismo religioso. Este proceso se ve estimulado por los contactos directos con planteamientos y prácticas culturales diversas de las formas tradicionales de vida. Actualmente, asistimos a las consecuencias de un proceso de ese tipo en el mundo musulmán, por ejemplo"

"El fundamentalismo islámico "conquista" un país tras otro; tras la "revolución islámica" en Irán, que trazó el camino a una nueva ideología radical, toda una serie de países se han vuelto a la sharia (algunos países africanos han adoptado ese código de leyes tradicionales, muchos de cuyos postulados contradicen los principios de la civilización contemporánea y los derechos humanos), mientras que los talibanes en Afganistán practicaban abiertamente el terror a escala nacional. Otro ejemplo; para los rusos, la introducción de la sharia en Chechenia y la celebración de ejecuciones públicas en las plazas, después de que esa república proclamara unilateralmente su independencia, constituyeron un verdadero impacto emocional".

Así llegamos a la conclusión: "Se puede afimar con toda certeza que con la suma de la destrucción de las culturas tradicionales y la destrucción de las formas tradicionales de vida —es menester recordar que la población urbana del planeta se duplicará en el próximo cuarto de siglo hasta alcanzar los cinco mil millones de personas- la pobreza no sólo porta el germen del aumento de la criminalidad, la drogadicción y la violencia, sino rambién del fundamentalismo religioso y, a la larga, el del terrorismo. Son numerosos los ejemplos que evidencian que el terrorismo surge sobre la base de ideas radicales, que se difunden entre los más desfavorecidos en los momentos críticos de la historia". Pero el problema se está presentando en los sistemas democráticos. 
"Al mismo tiempo, como convencido socialdemócrata que soy, también me alarma sobremanera el auge de la influencia de la ultraderecha en Europa" (Se refiere, más directamente - aunque no sólo- al caso del ultraderechista Jean Marie Le Pen en Francia). Sin embargo, no se puede explicar el auge de la extrema derecha tomándolo como una reacción a los procesos migratorios o a la fractura de las fuerzas democráticas. En mi opinión, las cosas son mucho más complejas. Se trata, en buena medida, de una reacción a los fracasos de la política económica, por una parte, y de la política social, por otra. El mantenimiento de las cifras de paro, especialmente entre los jóvenes, y en algunos casos su incremento constituye un reto para las instituciones democráticas y pone en duda su capacidad para la resolución de toda una serie de problemas que se van agravando. Los ciudadanos se sienten cada vez más alejados de los políticos y de las estructuras de poder, y buscan nuevas vías para poner de manifiesto su actitud de protesta. Actualmente, se ha hecho evidente que là crisis general ha alcanzado a los sistemas democráticos".

El hombre que intentó introducir al interior del socialismo soviético los valores de la transparencia, la verdad, las reformas económicas y sociales para convertirlo en una democracia de rostro humano, ahora se dirige, "como convencido socialdemócrata que soy", al capitalismo sin rostro humano para plantearle las crisis que visualiza en su interior y lo que Joseph Stiglitz ha llamado "el malestar en la globalización". Siendo el título de esta obra Carta a la Tierra, Gorbachov presenta una cuarta crisis mundial.

\section{Una crisis ecológica}

En varias partes de su más reciente libro, Gorbachov recuerda "la conmoción que me produjo el descubrimiento de la magnitud del desastre ecológico de la Unión Soviética". Esto no obsta para que inicie su comentario a la crisis ecológica con una referencia a nuestro capitalismo. "Cuando se produjo el hundimiento del sistema comunista mundial, el célebre oceanólogo Jacques Yves Cousteau declaró que el "responsable de los mayores daños infligidos a la naturaleza no había sido el comunismo, sino la economía de mercado en la que cada objeto tiene un precio, pero nada tiene valor". Aun cuando no apelo a la vuelta al comunismo —esa utopía ya se agotó en sí misma - me siento muy cercano a las palabras de Cousteau".

"La creciente crisis del medio ambiente muestra a las claras que la economía estrictamente liberal, para la que priman los criterios de 
rentabilidad y recuperación de las inversiones, es incapaz de enfrentar con éxito el reto que nos plantea la ecología. El mercado actual no concede valor alguno a aquello:que será más valioso para la gente dentro de cien años. ¿Qué valor mercantil puede otorgarse a la belleza de un lago o a la cima de una montaña cubierta de nieve? ¿Cómo justificar la salvación de especies animales que resultan tan "inútiles" si atendemos a los criterios de rentabilidad? Entretanto, un grupo de biólogos y economistas calcularon, en 1997, que los servicios que nos presta la naturaleza -el aire y el agua puros, las tierras fértiles- se podrían valorar en 33 billones (millones de millones) al año. La naturaleza no nos exige pago alguno por esos servicios. Mas, ino deberán nuestros descendientes pagar sumas similares, o aún mayores, para sanear la Tierra que nosotros nos hemos encargado de contaminar?".

"A pesar del carácter abierto de las sociedades occidentales y de las cada vez más insistentes llamadas de atención de ecologistas, biólogos, geógrafos y meteorólogos, la conciencia social se ha mostrado largo tiempo reacia a asumir esas informaciones en toda su gravedad, dado que hacerlo implicaría cambiar radicalmente nuestro modo de vida, nuestra moral y nuestros valores". Gorbachov hace referencia a la plegaria de Chemobil, comentando que para sepultar los residuos radioactivos los "liquidadores" tuvieron que echar capas y toneladas de tierra viviente, es decir, de especies vivas condenadas a su desaparición. ¿Qué derecho tenemos a disponer de la vida de otros seres vivos, a matarlos con el solo fin de protegernos de una catástrofe industrial causada por nuestra propia actividad que no hace más que arruinar su medio natural de vida". Gorbachov recuerda que mientras Estados Unidos sigue negociando el Protocolo de Kyoto la naturaleza sigue sufriendo serios daños ecológicos.

Gorbachov firma la introducción a su libro en Moscú, el día 26 de febrero de 2003, es decir, seis días después de la Cumbre de la Tierra en Johannesburgo. Recuerda los discursos fervientes que hubo en dicha cumbre de parte de varios Jefes de Estado. "Sin embargo, la mayor desilusión de la cumbre fue el resultado de las negociaciones sobre la crucial materia de la energía. Estados Unidos y otros países de la OPEP no estaban dispuestos a asumir ningún objetivo en materia de energías renovables, de manera que ahogaron la propuesta brasileña, respaldada por todos los países latinoamericanos y algunos otros países desarrollados y en vías de desarrollo, de cuadruplicar el uso de energía limpia hasta alcanzar el diez por ciento en 2010 ". 
El capítulo titulado “¿Qué hacer?”, recuerda la obra de Al Gore, $L a$ tierra en juego, por cuanto nos presenta la problemática generada por la degradación medioambiental tanto en la Unión Soviética como en el resto de continentes. Parte del concepto de desarrollo sostenible desarrollado por primera vez en la Conferencia de Naciones Unidas, Estocolmo 1972 y va siguiendo las agendas presentadas en la cumbre de Río Janeiro 1992, para terminar con los avances logrados en Johannesburgo - presentar la gravedad del problema ecológico en el nuevo milenio- lamentando los escasos compromisos en materia de energías renovables. Dada la seriedad del problema ecológico en El Salvador, este capítulo puede ofrecer datos y reflexiones importantes así como pistas para la investigación nacional. Extraigo algunas recomendaciones de $\mathrm{M}$. Gorbachov sobre qué se puede hacer, dada su sinceridad y experiencia como estadista, más que político.

"¿Cómo hacer para que la globalización redunde en beneficios para toda la humanidad?. Un objetivo tan vasto reclama ante todo una gestión global. Algunos han llegado a proponer un gobiemo planetario. Considero que es un proyecto utópico, antidemocrático, e incluso, peligroso. Mejor sería incrementar y hacer más eficaz la actividad de las instituciones internacionales de las que ya disponemos - las Naciones Unidas, el Banco Monetario Internacional, el Banco Mundial, la Organización Mundial del Comercio- dotarlas de poderes más amplios, para construir una única comunidad organizada de manera democrática, cuyos miembros sean los estados de la Tierra, todos con iguales derechos. Es extraordinariamente importante que cada vez que se adopten decisiones internacionales de orden económico se tomen en cuenta, sistemáticamente, los factores ecológicos y sociales. También lo es que se establezcan las reglas para un comercio internacional justo, que sea capaz de potenciar las economías locales y contribuya a la eliminación de la pobreza. Por último, es importante que se introduzcan mecanismos como la tasa Tobin, que controlen los mercados financieros, creando, de esa manera un mecanismo efectivo que garantice el desarrollo sostenible".

A buen entendedor, pocas palabras. "El proceso de toma de decisiones por parte de los organismos internacionales y su aplicación debe estar regido por la mayor transparencia. Y hay que pensar sobre todo en una reforma de las Naciones Unidas, en convertir su autoridad en una instancia inapelable. Cuando hay países que se comportan como vaqueros en el salvaje Oeste, no precisan de un mandato de la ONU para emprender acciones bélicas o policiales en territorio extranjero, no cumplen las 
resoluciones adoptadas por una aplastante mayoría de votos, está claro que esa organización no puede seguir existiendo en su forma actual. Tal situación no es más que una puerta abierta al caos y a los conflictos en un mundo que ha visto todo auge de los más diversos nacionalismos, donde, como si se tratara de una reacción alérgica a la globalización, se multiplican los síndromes arcaicos de hostilidad entre etnias y religiones, con explosiones de la más cruel violencia primitiva. Eso fue lo que sucedió, por ejemplo, en Ruanda".

A continuación, Gorbachov hace algunas sugerencias importantes a un tema espinoso, que estaba en la agenda de la última cumbre de la ONU, pero fue desviado a la vía muerta: la composición de su Consejo de Seguridad. "La ONU nació tras la segunda guerra mundial y, todavía hoy, su estructura refleja la situación generada por la victoria aliada sobre la Alemania nazi y el Japón imperialista, cuando el mundo fue dividido entre vencedores y vencidos. Nada puede explicar en nuestra época, salvo aquellas circunstancias, por qué esos dos inmensos países democráticos no forman parte del Consejo de Seguridad en calidad de miembros permanentes".

"Considero que ha llegado el momento de suprimir el artículo 53 de la Carta de las Naciones Unidas, que hace mención a los "Estados hostiles". Para aumentar el peso y la influencia del Consejo de Seguridad, para democratizarlo, propongo aceptar en él como miembros permanentes a países que también gozan de una gran autoridad en la escena internacional, como India, Italia, Indonesia, Canadá, Polonia, Brasil, México, Egipto, incluso si no se les concede el derecho al veto desde el principio. Finalmente, me gustaría exponer una idea que me es muy preciada y cuya implantación ayudaría a suplir el déficit moral que padece la política contemporánea. En todas las sociedades tradicionales, los ancianos gozan de un gran respeto y autoridad moral. ¿Por qué no crear, entonces, en el marco de la ONU un consejo de ancianos de la "aldea global", integrado por personalidades reconocidas y respetadas en el mundo de la ciencia y de la cultura, Premios Nobel, altos representantes de diferentes confesiones, eminentes hombres de Estado ya retirados? Los políticos actuales no pueden desconocer cuán necesaria es la humanización de la política". Gorbachov propone una lúcida reflexión a las alternativas planteadas en la última cumbre de la ONU y que quedaron en la vía muerta. (ECA 2005; pp. 859-862) 
-Teniendo en cuenta la gravedad de los problemas de la seguridad ecológica, de la frecuencia creciente de las catástrofes de origen natural o humano, me parece fundamental que se le concedan al Consejo de Seguridad plenos poderes en ese ámbito. Si bien yo no soy partidario de inflar las estructuras burocráticas, encontré muy atractiva la idea del ex primer ministro francés Lionel Jospin de transformar el Programa de la ONU para el Medio Ambiente en una organización mundial con competencias plenas. Una organización de ese tipo permitiría contrarrestar la influencia de las diferentes organizaciones económicas internacionales que orientan a los países en desarrollo hacia un modelo de economía de mercado pura, unificaría las numerosas convenciones internacionales ya existentes y velaría por su cumplimiento. Igualmente, una institución de ese tipo ejercería una presión real sobre los países que no se adhieran, o tarden en ratificarlos, a los acuerdos. Convenciones y otros protocolos internacionales concernientes al desarme, los cambios climáticos, la biodiversidad, la desertización o los recursos de agua". Realmente estamos escuchando a un estadista internacional que, por encima de toda ideología, busca el bienestar de toda la humanidad.

"Otra idea que no me canso de propugnar es la creación de un Tribunal Ecológico Internacional, según el modelo de la Corte Penal Internacional de La Haya, que realice, por una parte, funciones de arbitraje y, por otra, se encargue de juzgar a los países, o a empresas concretas, que sean reconocidos culpables de haber ocasionado perjuicios al entorno o a las poblaciones. Actualmente, en efecto, no disponemos de los medios jurídicos para castigar tales actos, sobre todo, paradójicamente, si la víctima es la humanidad en su totalidad. ¿Quién impondrá sanciones a los países que, habiendo ratificado el Protocolo de Kyoto -que presupone la reducción para el año 2012 de la emisión de gases que provocan el "efecto invernadero"- no cumplan con las obligaciones que han asumido? ¿Quién demandará a los países ricos del Norte por los daños ocasionados al entomo de los países pobres del Sur por la emisión de esos mismos gases".

Las últimas páginas de Carta a la Tierra están dedicadas a "Mi Cruz Verde", donde "narraré los orígenes de nuestra organización. La Cruz Verde es especialmente celosa en la vigilancia de las armas químicas. Es preciso recordar que a pesar de la existencia de la convención sobre la prohibición del desarrollo, la producción, el almacenamiento y el empleo de armas químicas y sobre su destrucción, firmada por 173 países y 
ratificada hace ya varios años por el Senado estadounidense y la Duma rusa, Estados Unidos posee aún unas veinticinco mil toneladas de ese armamento, distribuidas en ocho estados, mientras que Rusia tiene otras cuarenta mil ubicadas, sobre todo, en la parte europea del país".

"El principal obstáculo que se presenta hoy a la destrucción de las armas químicas es el elevado coste de esas operaciones, que sobrepasa ampliamente al de su producción. Estados Unidos debe gastar en total alrededor de veinte mil millones de dólares; Rusia, la mitad de esa suma. En mi calidad de presidente de Cruz Verde he hecho un llamamiento a los dirigentes de Estados Unidos y a los países europeos para que refuercen los montos que precisa Rusia". Lo interesante de este capítulo final es que nos ofrece abundantes datos sobre "las consecuencias ecológicas de las guerras y conflictos" y nos dice que "recuerdo cuando me enseñaban a usar el botón nuclear, tras convertirme en el máximo dirigente de la URSS. Confieso que incluso durante esas sesiones no llegué a tocar jamás el botón nuclear, si bien el maletín que lo contenía me acompañaba siempre".

Un año después de publicada Carta a la Tierra, en vísperas de conmemorar el tercer aniversario de los ataques terroristas del 11 de septiembre en Nueva York, un grupo de terroristas chechenos toma como rehenes a un millar de niños, familiares y profesores en la escuela de Beslan, Osetia del Norte, Rusia, y masacra a unas cuatrocientas víctimas inocentes. La masacre el 3 de septiembre en Beslan es un cruel golpe para los rusos, como el 11-S lo fue para los norteamericanos. "Tres semanas después de la carnicería de Beslan V. Putín se decide a poner en obra el fortalecimiento del poder central de los ministerios de Seguridad, Defensa e Interior. Más de cuarenta proyectos de ley se presentan al Parlamento para luchar contra el terrorismo internacional Las medidas programadas organizan el mayor control de extranjeros, limitan la circulación de personas y preven una censura de los medios de comunicación en caso de crisis. Se constituye una especie de gobierno paralelo en todo el Cáucaso del Norte (tierra natal de Gorbachov), desestabilizado por la guerra de Chechenia". Se trata de medidas similares a las impuestas por el ministro de Justicia de Estados Unidos luego del 11-Septiembre, y ambas potencias declaran "la guerra sin fin al terrorismo internacional". En esa oportunidad, Gorbachov dijo, para que lo oyeran ambos presidentes: "Un Gobierno no arregla sus problemas limitando los derechos de la ciudadanía". Carta a la Tierra es una actualización de Perestroika, con un cambio de tonalidad: "Nuevas ideas para el mundo y para mi país". 